\title{
Ridge-sail statistics at the shear edge of Lancaster Sound, March 1984
}

\author{
M. SAYed AND R. M. W. Frederking \\ Division of Mechanical Engineering, National Research Council, Ottawa, Ontario, Canada K1A OR6
}

\begin{abstract}
Ice-surface geometry at the shear edge of landfast ice has been examined. An aerial survey was conducted at the intersection of Lancaster Sound and Navy Board Inlet during March 1984. Surface profiles were then obtained in three representative areas and used to evaluate height statistics. A region, $150 \mathrm{~m}$ wide, at the ice edge was distinct from the rest of the ice cover. In the region at the shear edge, the surface height followed lognormal distributions. The average and maximum heights were $2.3 \mathrm{~m}$ and $5.6 \mathrm{~m}$, respectively. In the region inside the shear edge, the height followed negative exponential distributions, with average and maximum values of $1.5 \mathrm{~m}$ and $4.2 \mathrm{~m}$, respectively.
\end{abstract}

\section{INTRODUCTION}

Ice ridging in shear zones presents one of the major obstacles to navigation in many areas of the Arctic. There is a considerable literature dealing with the various aspects of ice ridging. Only a few studies that pertain to the present paper are referred to here. Those include the statistical models of Hibler and others (1972, 1974), Mock and others (1972), and Rothrock and Thorndike (1980). Periodicity of sails and keels were studied by Hibler and LeShack (1972) and by Kozo and Tucker (1974). Ridging in shear zones, which is particularly relevant to the present study, was investigated by Tucker and others (1979). Draft and spacing of ridges were examined extensively by Wadhams and co-workers; see, for example, Wadhams and Davy (1986). Ice-keel thickness and periodicity were also examined by Key and McLaren (1989). Comparisons of ridge statistics from several areas were reported recently by Weeks and others (1989) and by Krabill and others (1990).

To investigate the geometry of a shear zone, an aerial survey was conducted at the intersection of Lancaster Sound and Navy Board Inlet $\left(73^{\circ} 45^{\prime} \mathrm{N}, 81^{\circ} 30^{\prime} \mathrm{W}\right)$ during March 1984. A map of the study area is shown in Figure 1. Photographs were taken from $1525 \mathrm{~m}(5000 \mathrm{ft})$ and

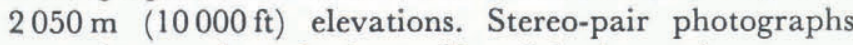
were then used to obtain profiles of the ice surface.

At that time, the central channel of Lancaster Sound was covered by freely drifting pack ice. A landfast-ice cover extended into the sound for a distance of about $6 \mathrm{~km}$ from Borden Peninsula. Landfast ice also covered all of Navy Board Inlet. The ice cover consisted mostly of firstyear ice with a few icebergs and isolated multi-year floes embedded in it. The landfast-ice surface was largely flat except near the edge, where ridges and hummock fields formed.

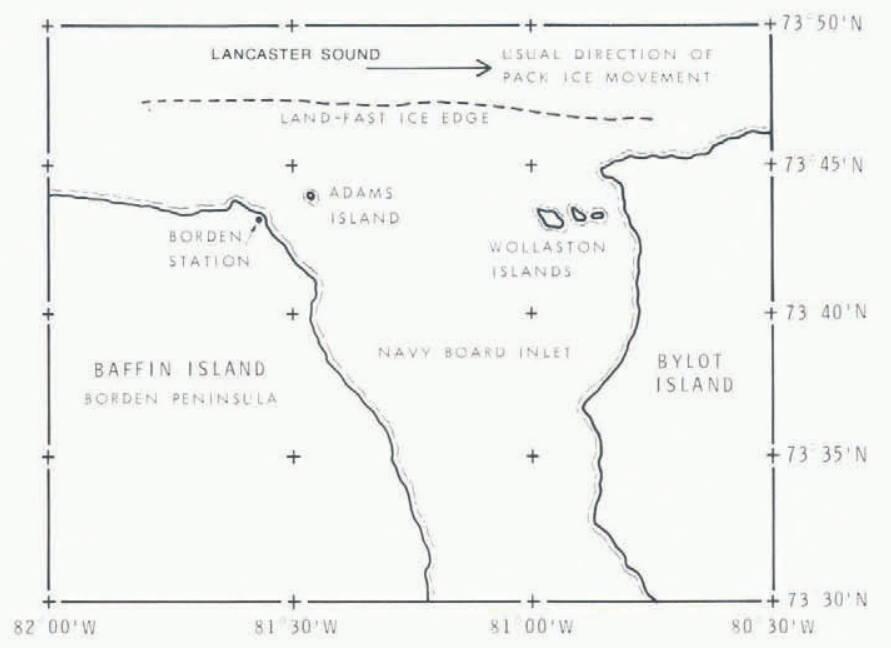

Fig. 1. Map of the study area.

Small representative areas were chosen to inspect ice geometry at the edge and further inside the landfast ice. This paper examines ice-rubble height statistical distributions and gives preliminary estimates of periodicities.

\section{DATA AND PROGEDURES OF ANALYSIS}

A photograph of the study area is shown in Figure 2a. Three areas were chosen for analysis. Two areas (nos. 1 and 2), each $400 \mathrm{~m}$ by $400 \mathrm{~m}$, were located at the edge. The third area (no. 3), which is $400 \mathrm{~m}$ by $800 \mathrm{~m}$, was inside the landfast ice at a distance of $2 \mathrm{~km}$ from the edge. Area 3 was to the west of the photograph and does not appear in Figure 2a. Enlarged photographs of areas 1 and 3 are shown in Figures $2 b$ and $2 c$. The dimensions of those 

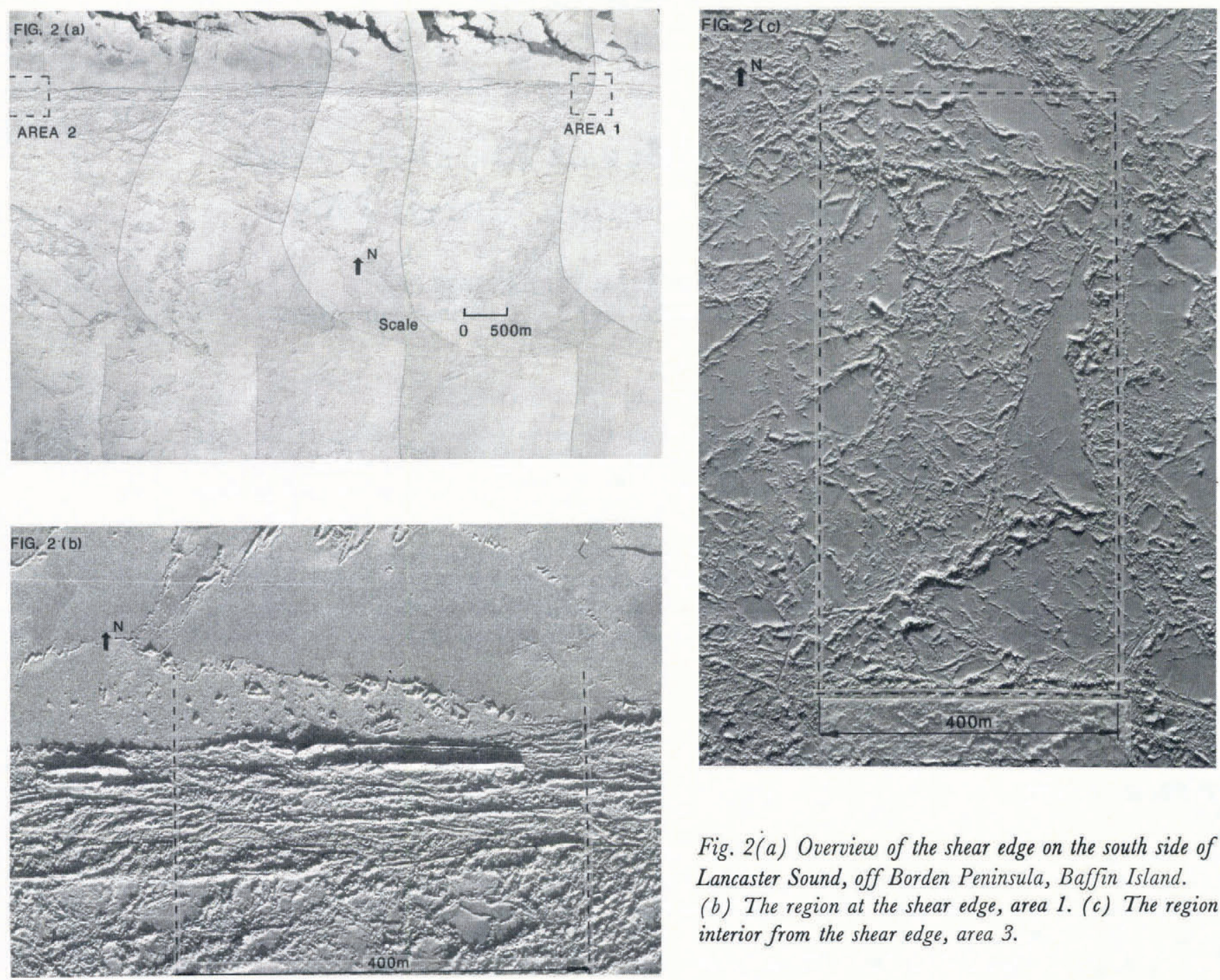

Fig. 2(a) Overview of the shear edge on the south side of Lancaster Sound, off Borden Peninsula, Baffin Island.

(b) The region at the shear edge, area 1. (c) The region interior from the shear edge, area 3.

areas were chosen sufficiently large to contain a reasonable number of ridges or hummocks. Because generating profiles from the photographs is relatively time consuming, the dimensions were not increased beyond what appeared to be adequate values.

From the photographs in Figure 2, it is clear that a strip near the landfast-ice edge consists of straight, and apparently shear-type, ridges and hummocks. Further inside the landfast ice, away from the edge, ridges follow meandering paths and appear to be of the pressure type. As distance from the edge increases, spacing between ridges increases, and ridge heights appear to decrease.

For areas 1 and 2, ice surface profiles were obtained along lines running approximately north-south (perpendicular to the shear edge) at $40 \mathrm{~m}$ intervals; i.e. for each area 11 lines, $400 \mathrm{~m}$ long, were profiled. Because rubble formations were parallel to the edge, there was no need to obtain profiles along other directions. For each profile, the horizontal distance and elevation were digitized as points where a change of slope was observed. Scale of the photographs used in the analysis is 1:10000. The corresponding accuracy of measured relative heights is estimated to be within $\pm 0.25 \mathrm{~m}$.

For area 3, profiles were obtained similarly along 11 south-north lines, each $800 \mathrm{~m}$ long, spaced at $40 \mathrm{~m}$ intervals. Those profiles are sufficient for the description

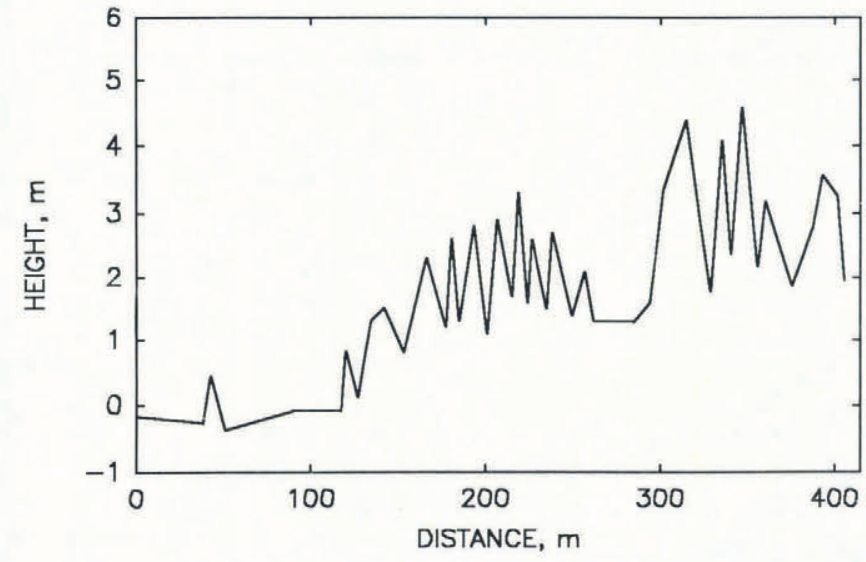

Fig. 3. Height profile at the shear edge (from area 1).

of height statistics over the area. A few additional profiles were also obtained along lines oriented at $45^{\circ}$ intervals.

Height values are determined here with respect to ice level in Lancaster Sound, outside the edge of landfast ice. That surface level of the apparently thin ice was probably close to water level. A respresentative ice surface profile from area 1 is shown in Figure 3. The left side of the profile corresponds to ice surface level in the sound at the north end of the line. Corrections of elevation in all profiles (in 


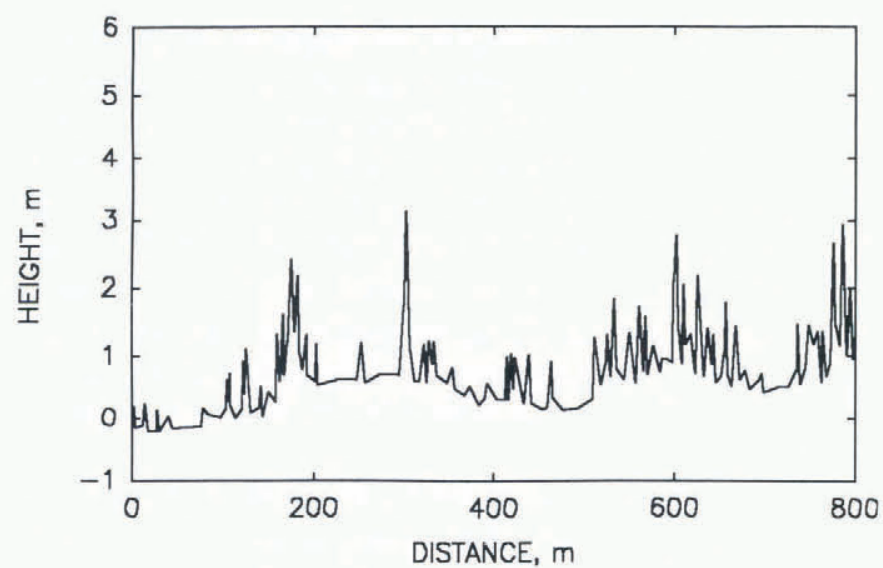

Fig. 4. Height profile interior from the shear edge (from area 3).

areas 1 and 2) were made to bring such levels to zero. It should be noted that the errors in measuring the absolute zero level, which were less than $0.5 \mathrm{~m}$, do not affect the accuracy of relative heights. A profile from area 3 is shown in Figure 4. All elevations in area 3 were adjusted to bring the lowest point in the entire area to zero. This was done by adding $0.3 \mathrm{~m}$ to all the original heights.

The profiles and photographs show that rubble hummocks, rather than distinct ridges, formed in a zone at the edge. Therefore, it is suitable to calculate height statistics in terms of fractions of a profile length (or of the area), and not in terms of discrete ridges. Consequently heights at $1 \mathrm{~m}$ horizontal intervals were calculated by linear interpolation (i.e. each line had 401 heights). Those calculated points are used in the subsequent analysis.

It should be emphasised that the present method of examining ice-rubble heights is different from that used in previous studies of ridge heights. Usually, individual ridges are identified using a certain criterion (see, for example, Hibler and others, 1972). Statistics are then evaluated using one value (the maximum height) for each ridge. Alternatively, the present method includes all heights of a ridge sail taken at $1 \mathrm{~m}$ horizontal interval.

Before proceeding with calculations of height statistics, it was necessary to eliminate small surface roughness values that do not result from ridging or hummocking (e.g. due to snow drifts or individual ice blocks). A cutoff value near $1 \mathrm{~m}$ is usually used; see, for example, Weeks and others (1989) and Krabill and others (1990). Only heights larger than the cutoff value are used to estimate the statistics. After trying several cutoff values, a value of $1 \mathrm{~m}$ appeared to suit the present data best.

\section{THE ICE EDGE}

Initial examination of the data revealed that height population in a zone, approximately $150 \mathrm{~m}$ wide, adjacent to the edge is different from that for the rest of areas 1 and 2, and all of area 3 . Therefore, it is necessary to divide the presentation of the results into two separate parts; one dealing with the region at the ice edge and the other dealing with the interior of the ice cover. The results in this section relate only to that $150 \mathrm{~m}$-wide zone at the ice-cover edge. Height histograms from areas 1 and 2 are
Table 1. Ridge height statistics

Location Average Maximum $\begin{array}{r}\text { Standard } \\ \text { deviation }\end{array}$
(m)
(m)
$(\mathrm{m})$

area 1

2.32

5.65

0.74

area 2

2.26

5.15

0.70

area 3

1.49

4.17

0.48
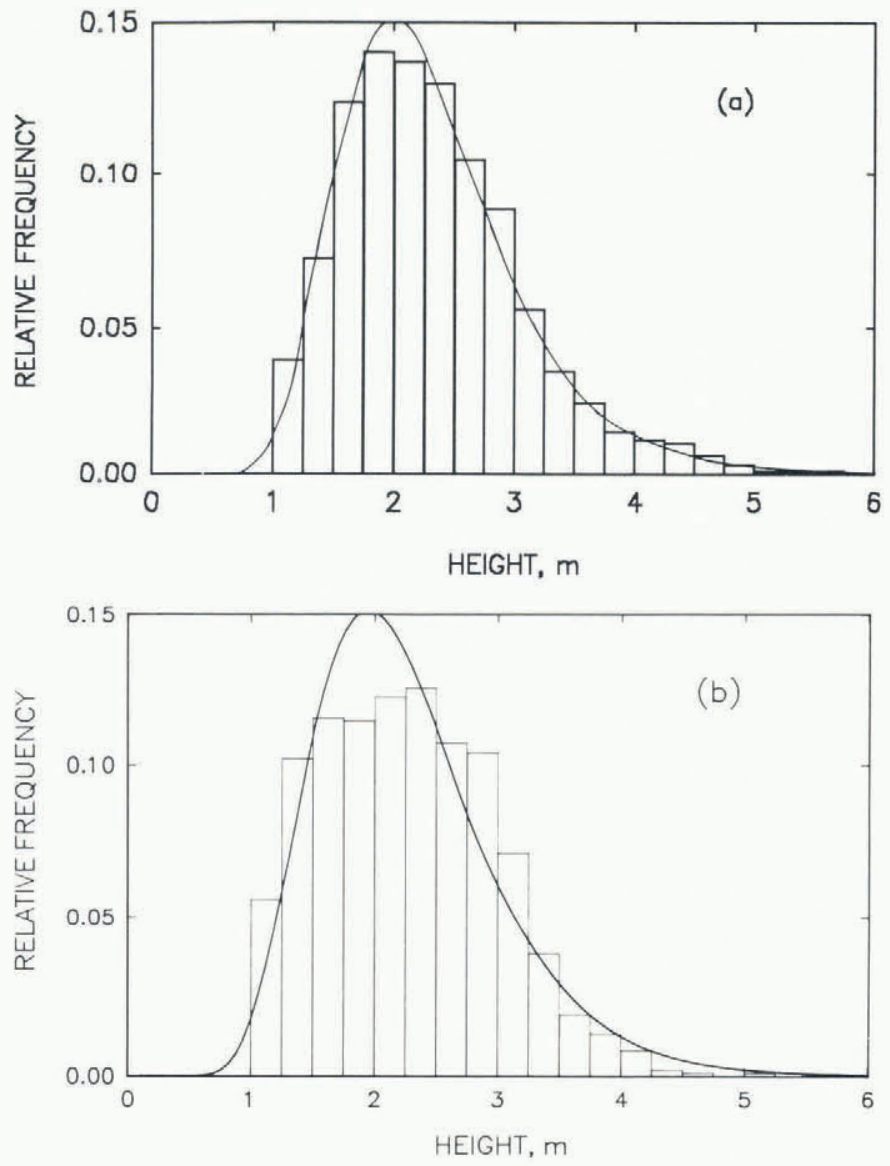

Fig. 5. Height histograms and lognormal distribution curves from the region at the shear edge, (a) area $1,(b)$ area 2.

shown in Figure 5, and summary statistics are given in Table 1 . There is very little variation between the height histograms for individual profiles within each area. The shapes of the histograms in Figure 5 suggest that they may be represented by lognormal distributions. Fits of such distributions were attempted, and the goodness-of-fit was examined using the $\chi^{2}$ test. The lognormal distribution curves are shown in Figure 5. A good fit was obtained for the dataset that contains all heights in area 1 . With 18 degrees of freedom, a total $\chi^{2}$ of 27 was obtained, which is acceptable at the $5 \%$ level of significance. Area 2 was 
more complicated. A good fit for the entire area could not be obtained. With 18 degrees of freedom, a total $\chi^{2}$ of 152 was obtained, which is not acceptable at the $5 \%$ level. Therefore, fitting for heights belonging to individual profiles was attempted. Heights from some profiles, mostly in the western half of area 2, passed the $\chi^{2}$ test at the $5 \%$ level. The fitting for heights from other profiles, mostly from the eastern half of area 2 , was not acceptable at the $5 \%$ level.

Hummocking and ridging in areas 1 and 2 is evidently anisotropic, and occurs mostly along lines parallel to the ice edge. A preliminary examination of the periodicity of surface height in a direction perpendicular to the edge was conducted. Spectral analysis was used to determine the significant wavelengths. This approach has been used in a number of studies of ridge spacing; see, for example, Hibler and LeSchack (1972), Kozo and Tucker (1979) and Key and McLaren (1989). A power spectrum was obtained for each profile in areas 1 and 2. Note that this was done for all the data without eliminating the heights that are below the cutoff value; i.e. horizontal spacing was uniform at $1 \mathrm{~m}$. Nevertheless, the heights over the entire $150 \mathrm{~m}$-wide region were mostly over $1 \mathrm{~m}$; i.e. hummocking was continuous. The resulting significant peaks of the spectra correspond to a range of wavelengths. Some are close to $25 \mathrm{~m}$ and others are in the neighbourhood of $15 \mathrm{~m}$ to $17 \mathrm{~m}$. This inspection of significant wavelengths is somewhat descriptive. More rigorous and accurate approaches such as those of Kozo and Tucker (1979) and Key and McLaren (1989) should be used. It is, nonetheless, outside the scope of this paper to pursue such an approach because of space limitations.

\section{THE INTERIOR ICE COVER}

The height histogram for area 3 is shown in Figure 6 and summary statistics are given in Table 1 . The shape of the height histogram suggests that the negative exponential distribution of Hibler and others (1972) may be suitable. The following equation of Hibler was used:

$$
P(h) \mathrm{d} h=2 \bar{h} \lambda \exp \left(\lambda h_{0}^{2}\right) \exp \left(-\lambda h^{2}\right) \mathrm{d} h,
$$

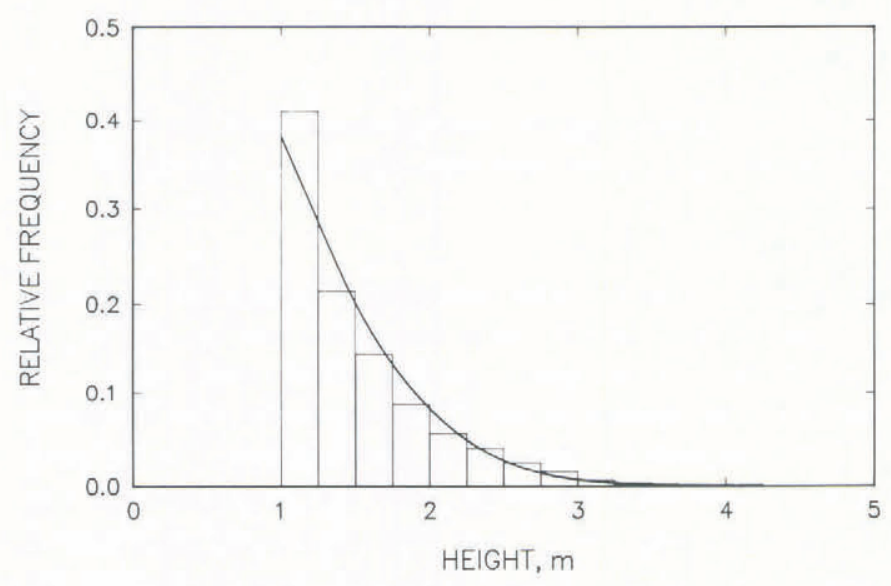

Fig. 6. Height histogram from the region interior to the shear edge (Area 3). Hibler's equation is also shown as a continuous curve. where $P(h)$ is the probability of the height being between $h$ and $h+d h, h_{0}$ is the cutoff height and $\bar{h}$ is the average height. The resulting probabilities were adjusted for the bin size of the data and plotted as a continuous curve in Figure 6. For $\lambda=0.51 \mathrm{~m}^{-2}$, and with 8 degrees of freedom, a total of $\chi^{2}$ of 147 was obtained. This fit is not acceptable at the $5 \%$ level. The trends of Hibler's equation, however, are in agreement with those exhibited by the data. This agreement could be fortuitous, since Hibler's equation was developed for statistics of maximum ridge heights.

Average heights predicted by the present method are expected to be lower than those obtained using the maximum heights of individual ridges. This difference is examined briefly by considering the profile shown in Figure 4. Individual ridges were identified as peaks, where surface slope changes from positive to negative. The present method of using all rubble heights gives an average height of $1.43 \mathrm{~m}$ for that profile. When maximum heights of individual ridges are used, an average height of $1.83 \mathrm{~m}$ was obtained; i.e. the present method reduces the average height estimate by $22 \%$.

A measure of ridging intensity, instead of ridge spacing, is obtained by considering the fraction of profiles length that corresponds to heights above the cutoff value. The ratio of such ridged length to the total length was 0.46 . Periodicity of the height in varying directions was also examined for this area, since isotropy was not evident. This cursory examination of periodicity can only indicate that some wavelengths close to $30 \mathrm{~m}, 24 \mathrm{~m}$ and $14 \mathrm{~m}$ appear to correspond to significant peaks of the power spectrum.

\section{DISCUSSION OF THE RESULTS}

Comparison between the present results and observations from other areas of the Arctic is difficult because the present method of estimating height statistics is different from those used in previous studies. All heights are considered here, whereas maximum ridge heights (one value per ridge) were used in the available literature. The present study has also concentrated on areas where icerubble heights were prominent; i.e. height estimates are biased towards extreme values. It is a coincidence, therefore, that the present average height in the interior of the ice cover $(1.5 \mathrm{~m})$ is close to average heights observed in several other areas (Weeks and others, 1989). Maximum heights, however, should not be affected by the difference between methods of calculations. The maximum height of $5.6 \mathrm{~m}$ at the shear edge is consistent with the measurements of Tucker and others (1979) in the vicinity of shear zones in the Chukchi and Beaufort seas.

The preceding results show that, in the region of Lancaster Sound under consideration, the shear edge presents a substantial obstacle to navigation. Rubble formations at the shear edge were much larger than adjacent ridged ice. An approximate estimate of ice-rubble thickness can be made by assuming a ratio of average keel depth to average sail height. If a ratio of 3.5 is assumed, which is the minimum reasonable estimate, the total rubble thickness would be over $10 \mathrm{~m}$. This value is substantial compared to the maximum $2 \mathrm{~m}$ thickness of the ambient first-year ice. 


\section{CONGLUSION}

Ice rubble at the shear edge of landfast ice formed an approximately $150 \mathrm{~m}$-wide zone which was distinct from the region further inside. At the edge, ice rubble consisted of hummocks that were straight, apparently of a sheartype, and parallel to the edge. No distinct ridges, with flat ice between them, were present in that zone. Lognormal distributions gave a good fit for the data from two representative areas. The average heights in those two areas were $2.26 \mathrm{~m}$ and $2.32 \mathrm{~m}$; the maximum values were $5.15 \mathrm{~m}$ and $5.65 \mathrm{~m}$.

For the region well inside the ice-cover edge, surface geometry appeared to be more isotropic. The roughness consisted mostly of pressure-type, meandering ridges. Heights were lower than those near the edge. The average value was $1.49 \mathrm{~m}$ and the maximum was $4.17 \mathrm{~m}$. Negative exponental distributions provided good fits for the heights.

\section{ACKNOWLEDGEMENTS}

The aerial photographs were taken by P. Roy. His technical help is greatly appreciated. The logistic support provided by the Polar Continental Shelf Project is gratefully acknowledged. This study was supported financially by the Panel on Energy Research and Development and the Canadian Coast Guard.

\section{REFERENGES}

Hibler, W.D., III, and L.A. Leschack. 1972. Power spectrum analysis of undersea and surface sea-ice profiles. F. Glaciol., 11(63), 345-356.

Hibler, W.D., III, W.F. Weeks, and S.J. Mock. 1972. Statistical aspects of sea-ice ridge distributions. 7 . Geophys. Res., 77(30), 5954-5970.

Key, J.R. and A.S. McLaren. 1989. Periodicities and keel spacings in the under-ice draft distribution of the Canadian basin. Cold Reg. Sci. Technol., 16(1), 1-10.

Kozo, T.L. and W.B. Tucker, III. 1974. Sea ice bottomside features in the Denmark Strait. F. Geophys. Res., 79(30), 4505-4511.

Krabill, W.B., R.N. Swift, and W.B. Tucker, III. 1990. Recent measurements of sea ice topography in the eastern Arctic. CRREL Monogr. 90-1, 132-136.

Mock, S.J., A.D. Hartwell, and W.D. Hibler, III. 1972. Spatial aspects of pressure ridge statistics. 7. Geophys. Res., 77(30), 5945-5953.

Rothrock, D.A. and A.S. Thorndike. 1980. Geometric properties of the underside of sea ice. F. Geophys. Res., 85(C7), 3955-3963.

Tucker, W.B., III, W.F. Weeks, and M. Frank. 1979. Sea ice ridging over the Alaskan continental shelf. J. Geophys. Res., 84(C8), 4885-4897.

Wadhams, P. and T. Davy. 1986. On the spacing and draft distributions for pressure ridge keels. 7. Geophys. Res., 91 (C9), 10,697-10,708.

Weeks, W.F., S.F. Ackley, and J. Govoni. 1989. Sea-ice ridging in the Ross Sea, Antarctica, as compared with sites in the Arctic. F. Geophys. Res., 94(C4), 4984-4988.

The accuracy of references in the text and in this list is the responsibility of the authors, to whom queries should be addressed. 